\title{
The health care system reform in China: Effects on out-of-pocket expenses and saving
}

\author{
Vincenzo ATELLA ${ }^{\mathrm{a}, 1}$, Agar BRUGIAVINI ${ }^{\mathrm{b}, 2}$, Noemi PACE ${ }^{\mathrm{b}, *}$ \\ ${ }^{a}$ Centre for Economic and International Studies (CEIS), Department of Economics and Finance, University of Rome Tor Vergata, Via Columbia 2, 00133 Rome, Italy \\ b Department of Economics, University Ca' Foscari of Venice, Cannaregio 873, 30121 Venezia, Italy
}

\section{A R T I C L E I N F O}

\section{Article history:}

Received 11 July 2014

Received in revised form 13 February 2015

Accepted 13 February 2015

Available online $\mathrm{xxxx}$

\section{JEL classification:}

D14

I13

P36

Keywords:

China

Health insurance

Health care system reform

Household saving

Out-of-pocket expenditures

\begin{abstract}
A B S T R A C T
This paper aims to evaluate the impact of 1998 Chinese health care reform on out-of-pocket expenditure and on saving. Existing evidence on the results achieved by this reform in terms of reduction of out-of-pocket medical expenditures is still mixed and contradictory, and very little is known about the impact of these measures on the consumption and saving behavior of the Chinese population. To shed more light on this issue we use data collected in 1995 and 2002 by the Chinese Household Income Project (CHIP). Contrary to previous evidence, our findings suggest that the effects of the reform have been more articulated and heterogeneous. In fact, we find that once properly accounting for income distribution and unobserved heterogeneity (potentially induced by health status), out-of-pocket medical expenses and saving rate are affected by the reform in a differentiated way. In particular, we find that out-of-pocket expenses decrease only for high income individuals with good health status and the saving rate increases only for low income individuals with good health status. This result is actually worrisome, as it suggests that the public health coverage after the reform provides financial protection only to individuals that are relatively better off (with good health status and/or high income).
\end{abstract}

(c) 2015 Elsevier Inc. All rights reserved.

\section{Introduction}

The characterization of the determinants of households' saving decisions is important both for providing a framework to explain household wealth accumulation per se, as well as for providing valuable information on a variety of welfare policies. Given the large size of the Chinese economy and its importance at the international level, considerable effort has been devoted in the economic literature to understand Chinese households' saving decisions.

In the '70s, China has launched several reforms affecting the economy and, in particular, the social security system. The main objective of these reforms was to transform China's stagnant, impoverished and centrally planned economic system into a more flexible and decentralized system capable of generating sustained economic growth and increasing the well-being of Chinese citizens. The reforms began in 1978 and occurred in two stages. The first stage, between the late '70s and the early ' 80 s, involved the decollectivization of agriculture, the opening up of the country to foreign investments, and the permission for entrepreneurs to start up businesses. However, most industries remained state-owned. The second stage of the reform, between the late '80s and the '90s, involved the privatization and contracting out of much state-owned enterprises (SOEs) and the removal of price controls, protectionist policies, and redundant regulations, although state monopolies in sectors such as banking and petroleum remained

\footnotetext{
* Corresponding author. Tel.: + 390412349187 ; fax: + 390412349176.

E-mail addresses: atella@uniroma2.it (V. Atella), brugiavi@unive.it (A. Brugiavini), n.pace@unive.it (N. Pace).

1 Tel.: + 39 0672595606; fax: + 39062020687.

2 Tel.: + $390412349162 ;$ fax: +390412349176.
} 
state-owned. Following these changes, the private sector grew remarkably, accounting for as much as 70\% of China's GDP by 2005 , reaching a figure larger than the GDP of Western nations. Along with the economic reform, the period between the end of the ' $80 \mathrm{~s}$ and the middle of the '90s was characterized by low real interest rate which might have induced an increase in saving rate, given the borrowing constraints faced by households and small enterprises (Aaberge \& Zhu, 2001; Modigliani \& Cao, 2004; Nabar, 2011). Within the same period, the Chinese government also implemented a series of reforms in the social security sector, including the pension system.

The saving rate of urban Chinese households was basically flat before the '70s, but it started to increase as from 1978 , until the beginning of the '90s and reached a percentage as high as 35\% of GDP (Modigliani \& Cao, 2004). The average saving rate of urban households relative to their disposable income rose from 17\% in 1995 to 24\% in 2005 (Chamon \& Prasad, 2011; Yang, Zhang, \& Zhou, 2010). Several studies, based on classical models of saving have been used to explain the pattern of consumption/saving in developed market economies. In particular, well established models, such as the Modigliani-Brumberg's life-cycle theory and Friedman's permanentincome hypothesis, are taken into account as theoretical ground to try to explain the Chinese household's saving behavior. However, the results predicted by these theories are not supported by the findings of empirical studies on the Chinese household saving behavior (Chow, 1985; Modigliani \& Cao, 2004; Qian, 1988; Wang, 1995). One challenging fact that hardly reconciles with the life-cycle theory is the age-saving profile of the Chinese household: it shows a U-shaped pattern (Brugiavini, Weber, \& Wu, 2013; Chamon \& Prasad, 2011), which is inconsistent with the hump-shaped pattern predicted by the life-cycle hypothesis. Moreover, empirical studies have provided evidence of the increased uncertainty related to income and consumption induced by the economic sector reforms and, as a consequence, an increase of precautionary savings (Kraay, 2000; Ma \& Yi, 2010). Other studies using a simple growth model have shown that uninsured risk induced by the economic transition partially altered the relation between the marginal propensity to consume and the permanent income. Instead of consuming, the high income households prefer to save more (Wang \& Wen, 2011; Wen, 2010).

The aim of this paper is to focus on the health care system reform undertaken in 1998 and on its potential effects on household outof-pocket expenses and saving. We extend the descriptive analysis provided by Atella, Brugiavini, Chen, and Pace (2014) to investigate, through an econometric analysis, the causal relationship between the health care reform and out-of-pocket expenses and saving. To the best of our knowledge, this is the first contribution addressing together these research questions.

Within this literature, several authors have investigated the effect of various determinants of household saving rate (Brugiavini et al., 2013; Chamon \& Prasad, 2011; Choukhmane, Coeurdacier, \& Jin, 2013; Feng, He, \& Sato, 2011; Wei \& Zhang, 2011) but to date there are no contributions studying the relationship between the health care reforms and saving using microdata. The only two papers that focus on the relationship between saving rates and the reforms occurred in the health care sector are Barnett and Brooks (2010) and Baldacci et al. (2010), but they use macrodata and cannot assess the role of heterogeneity. ${ }^{3}$ On the contrary, there are several contributions studying the relationship between the health care reforms and out-of-pocket expenditure (see for example Liu \& Zhao, 2006; Yip \& Hsiao, 2009; Wagstaff \& Lindelow, 2008; Liu, Rao, Wu, \& Gakidou, 2008), although the results are a bit mixed.

The remainder of this paper is organized as follows: Section 2 reviews the institutional background of the health care system; Section 3 describes the data, the econometric model and the estimation results. Finally, Section 4 concludes.

\section{The health care sector reform in urban China}

Before 1998, the Chinese urban health insurance system consisted mainly of two insurance schemes: i) the Labor Insurance Schemes (LIS) that bore all costs of medical treatment, medicine and hospitalization for the workers and for their dependents; and ii) the Government employee Insurance Scheme (GIS) under which medical costs were covered by government budgetary allocation. ${ }^{4}$ While GIS and LIS have played an important role in providing China's urban working population with health protection, several aspects of the original schemes contributed to China's rapid health care cost inflation and inefficient resource allocation. First of all, GIS and LIS were third-party insurance, providing comprehensive benefits with minimal cost sharing. Second, insured individuals receive largely free outpatient and inpatient services. This limited consumer financial responsibility for the health services utilization induced over-utilization of health care services. Moreover, both GIS and LIS beneficiaries seek medical services from public hospitals, which are usually reimbursed on a fee-for-service basis according to a government-set fee schedule. This system gives providers incentive to over-provide services (Liu, 2002).

For this reason, during the ' 80 s, China started to implement a whole series of reforms in the urban health insurance system. During the first stage of the reforms (early '80s to 1991) the primary objective was cost containment and major reform measures include the introduction of demand-side cost sharing and, on the supply side, more controls on the provider's activities. During the second stage (1992-1998), the health sector reforms addressed the issue of inadequate risk pooling. Two cities in Jiangxi and Jiansu Province began pilot reforms that used a combination of individual savings accounts and social risk-pooling funds to finance medical expenditures.

\footnotetext{
${ }^{3}$ Barnett and Brooks (2010) pool provincial data in China from 1994-2008 to exploit variations in provincial spending on health and differences in saving rates. Their results suggest a statistically significant negative relationship between government health spending and saving in urban areas. Baldacci et al. (2010) examine the impact of expanding social programs on household consumption in China. They simulate the effects of alternative government social expenditure reforms on aggregate consumption using estimates of the age-specific marginal propensities to consume for different income groups and estimates of the lifetime amount of resources available to each cohort. They find that a 1 percentage point of GDP increase in social expenditures allocated across pension, education and health would result in a permanent increase in household consumption of $1.2 \%$ of GDP.

${ }^{4}$ In this section we provide a short description of the health care system before and after the reform undertaken in the 1998 . More details are provided by Wagstaff, Yip, Lindelow, and Hsiao (2009) and by Atella et al. (2014), to which we refer interested readers.
} 
Before an individual could access the social risk-pooling fund, however, he or she must first pay deductibles from a first tier of individual medical savings account and a second tier of direct deductible equal to $5 \%$ of annual income.

At the end of 1998, the Chinese government established a social insurance program for urban workers that replaced the existing LIS and GIS in the cities, known as Basic Insurance Scheme (BIS). The program is financed by premium contributions from employers ( $6 \%$ of the annual employee's wage) and employees ( $2 \%$ of their annual wage). ${ }^{5}$ Retired workers are exempt from premium contributions and the cost of their contributions is to be borne by their former employers. ${ }^{6}$ Compared with the old GIS and LIS, the new program expands coverage to private enterprises and smaller public enterprises. Moreover, self-employed workers are allowed to enter the program. However, compared with the old system of GIS and LIS, the benefit structure under the new system has two major gaps in coverage. First, the dependents of the urban workers, who used to receive partial coverage, are no longer covered. Second, the new system has a ceiling on the insured amount of the individual medical expenditures (equivalent to four times the annual average wage in the region). Imposition of this ceiling is due to budget constraints as well as the political emphasis on the wide coverage, but it leaves most catastrophic illnesses uncovered.

The Ministry of Labor and Social Security (1999) estimated that the premium contribution based on the $8 \%$ of the current wage can only cover about 70\% of the total outlay under the old systems of GIS and LIS. Moreover, Gao, Raven, and Tang (2007) show that the proportion of elderly covered by health insurance in urban China has declined over the period 1998-2007. ${ }^{7}$

\section{Data and empirical analysis}

The empirical analysis of this paper is based on cross-sectional data obtained from the Chinese Household Income Project surveys (CHIPs) conducted by the Chinese Academy of Social Science (CASS) in 1988, 1995 and 2002. The surveys use sub-samples from the main nationally representative household survey program conducted by the Chinese National Bureau of Statistics in the urban and rural areas, and are designed to be representative of the whole Chinese population. For the scope of our analysis, we only focus on the 1995 and 2002 waves that represent respectively the pre-reform and post-reform periods. We exclude from the analysis the 1988 wave because there are incomplete information on income and expenditure. Furthermore, we do not consider the rural sample because the Basic Insurance Scheme (BIS) was introduced only in the urban areas. ${ }^{8}$ The urban sample included individuals and households from 11 provinces and municipalities. ${ }^{9}$ The purpose of CHIPs urban data collection was to measure the distribution of personal income. Moreover, the data provide a large set of information on each household member concerning his/her social and economic status, including employment characteristics, wage, tax, and sources of income, and demographic variables such as, age, gender, marital status, relationship to the household head. Information is also gathered on household's expenditures and on their living conditions. ${ }^{10}$

\subsection{Data description}

The empirical analysis will be performed at household level, with some information collected at the head of the household level (socio-demographic and employment characteristics) and some other at the household level (income, expenditures and saving). Given the current structure of the Chinese health care assistance and our focus on saving behavior, we restrict the sample to include only household heads aged 25-65, and we exclude household heads who are self-employed, employed without contract or employed with short and temporary term contract (in total 434 observations). Moreover, to avoid potential measurement errors, we dropped the extreme values of the saving rate (values of the saving rate below the first percentile and above the 99th percentile). After performing these selections we obtain a sample of 6445 households in 1995 and 5869 households in 2002. However, for our empirical analysis the sample size reduces to 5305 households in 1995 and to 4194 in 2002, as the survey contains a non-negligible number of missing values for the income and some employment characteristic variables used as regressors.

Table 1 reports the summary statistics (based on the final sample) of the variables used in the empirical analysis.

\footnotetext{
${ }^{5}$ The amount of the employer's contribution was different across provinces and cities. The average contribution level was $6 \%$ of the employee's wage.

${ }^{6}$ Liu (2002) provides an extensive description of the characteristics of BIS.

${ }^{7}$ This may be attributed to the reform of state-owned enterprises, which has resulted in many enterprises being closed and a substantial number of workers being laid off (Gao et al., 2001). As only the minimum living allowance was guaranteed, the elderly who were laid off or whose employing enterprises were closed as a result of the ongoing economic reforms process may have lost their entitlements, such as the health insurance.

${ }^{8}$ In our view using the rural sample as control group may not represent a good identification strategy for at least two reasons. First, the health insurance system in urban and rural areas are completely different and were always managed as two completely different sectors (Atella et al., 2014; Brown, De Brauw, \& Yang, 2009; Carrin et al., 1999; Gao et al., 2007; Liu, 2002). Second, since the beginning of the economic reform and also during the period 1995-2002 (the study period of the current paper) the rural and urban areas have been affected by different reforms of the economic and welfare system or by the same kind of reform but undertaken in different years and under different rules (e.g. the "one child policy", the pension reform, etc.).

9 In the 1995 wave, the 11 provinces and municipalities are Anhui, Beijing, Gansu, Guangdong, Henan, Hubei, Jiangsu, Liaoning, Shanxi, Sichuan, and Yunnan. In the 2002 wave, Chongqing municipality is also included. Since it was one of the cities of Sichuan province and became the municipality in 1997, we combine Chongqing and Sichuan together in the 2002 wave. These 11 provinces and municipalities cover all the 6 geographical areas and can reflect the economic situation of China. In 2002, Guangdong ranked the first in GDP and Beijing municipality ranked the first in per capita GDP, whereas Gansu ranked the 25th in GDP over all the Chinese 31 provinces and was one of the lowest per capita GDP all over the country; Liaoning was heavy industry center, where petrochemical industry, machinery manufacturing industry and metallurgy industry occupied $70 \%$ of total Liaoning gross industrial output value; Henan was the most important agriculture province, where cultivated area ranked the first all over the country (National Bureau of Statistics of China, 2003).

${ }^{10}$ In the 2002 wave, CHIPs provide two special data sets which investigate rural-to-urban migrant individual and household information. However, such data do not exist in the 1995 wave. Therefore we do not take these rural-to-urban migrant households into account in our analysis.
} 
Table 1

Household income, expenditure, saving rate and OOP expenses.

\begin{tabular}{lccc}
\hline Variable & 1995 & 2002 & t-Stat \\
\hline Total household disposable income & 5092.3 & 7444.9 & 36.74 \\
Total household expenditures & 4248.8 & 5528.5 & 27.56 \\
Saving rate & 13.3 & 22.2 & 17.20 \\
OOP medical expenses & 125.6 & 348.9 & 17.37 \\
OOP medical expenses-income ratio & 0.025 & 0.047 & 12.66 \\
\hline
\end{tabular}

Notes: The total household disposable income, household expenditure and the out-of-pocket expenses are reported in 2011 US dollar. The fourth column shows the absolute t-value of a standard test of mean difference across the two surveys. Data source: Chinese Household Income Project (1995, 2002) and authors' calculations.

The measure of disposable income that we focus on includes labor income, property income, transfers, and income from household sideline production minus income tax. The consumption expenditure variable covers a broad range of categories. ${ }^{11}$ Out-of-pocket medical expense is defined as the difference between total household's health care expenditure and the amount of the reimbursement by any kind of health insurance. Furthermore, we measure savings as the difference between disposable income and consumption expenditure and we define the saving rate as the ratio between saving and disposable income. All flow variables are expressed in 2011 U.S. dollars, PPP adjusted, and nominal variables in 2002 are deflated using the national CPI (base year $1995=100$ ).

An important feature of the data used in the analysis is worth to be discussed: our key variables may suffer from measurement error. Indeed, individuals may tend to under-report their own income, consumption expenditure and the reimbursement received from the health insurance. As a consequence, our measures of household saving and out-of-pocket expenditure may be biased. In particular, if the underestimation of income is lower than that of consumption expenditure, and if reimbursement is underreported, our measures of saving and out-of-pocket expenditure may be overestimated. The problems that originated in the empirical analyses by measurement error in income and consumption are widely known among researchers and there are several contributions in the literature that discuss these issues. Although this is not the right place where to speculate on such issues, it is worth mentioning that Moore, Stinson, and Welniak (2000) and Pedace and Bates (2000) have produced a comprehensive review on the measurement issue in income variables. Similarly, Attanasio, Battistin, and Ichimura (2004), Attanasio and Weber (2010), Battistin (2003), Crossley and Winter (2012), and Pudney (2008) have reviewed the same issues on the consumption side. Moreover, a paper by Cifaldi and Neri (2013) studies the issue of measurement error in household survey for both income and consumption expenditure. Concerning China, only few papers have pointed out the possible underestimation of China's household consumption (among the others, Wang \& Zhang, 2009; Perkins, 2012; Zhang \& Zhu, 2014). Most of these papers agree on the underestimation of household consumption and some have tried to estimate the extent of the error (Peng et al., 2012; Zhu \& Zhang, 2012). Unfortunately, to the best of our knowledge, there are no studies which focus specifically on the issue of heterogeneity in the underestimation of consumption and reimbursement. Moreover, we did not find any study on the correlation between measurement error and insurance type in China.

However, we believe that the potential under-reporting of reimbursement and consumption and the consequent overestimation of out-of-pocket expenditure and saving rates could be a major problem in our empirical analysis only if the bias is heterogeneous across the sample. We will carefully address this point from an empirical point of view in Section 3.2.

Conditional on these caveats on the quality of the data, in Table 1 we observe that, on average, the household's total and disposable income increased significantly in real terms from 1995 to 2002. Accordingly, also the household total expenditure increased significantly, even though the rate of growth of expenditure is lower than what we observe for the income variables. Moreover, the average out-of-pocket medical expenses increased significantly from 1995 to 2002 which is consistent with the findings of Gao, Tang, Tolhurst, and Rao (2001) and Wagstaff and Lindelow (2008). Finally, the average ratio between out-of-pocket medical expenses and disposable income was 0.025 in 1995 (ranging from 0 to 0.97 ) and 0.047 in 2002 (ranging from 0 to 3.36). The household saving rate and the ratio between out-of-pocket medical expenses and disposable income are the dependent variables in the econometric analysis presented in the next section.

There are several possible explanations for the increase in total household expenditure, but in our paper we focus on two main reasons. First, in 1995 the health care costs of the LIS and GIS beneficiaries' dependents could be partially reimbursed, whereas in 2002 BIS did not reimburse the dependents' health care costs any more. Second, during this period there was a remarkable health care cost increase, which leads to higher household health care expenses. Moreover, the proportion of the public insurance coverage decreased from 1995 to 2002 significantly. This result is not surprising, since the Ministry of Labor and Social Security (1999) reported that BIS could only cover 70\% of the total outlay under GIS and LIS. This may be attributed to the reform of SOEs which has resulted in many enterprises being closed and a substantial number of workers being laid-off (Gao et al., 2001).

Table 2 and Fig. 1 provide information on the average saving rate by age group. For all age groups the saving rate is higher in 2002. Moreover, in both waves, the saving rate has a U-shape pattern. Coherently with previous empirical analyses run by Yang et al. (2010), Chamon and Prasad (2011) and Brugiavini et al. (2013) we also find that the lowest saving rate levels are registered among the 30-44 age group in 1995 and among the 35-49 age group in 2002.

\footnotetext{
${ }^{11}$ Consumption expenditure includes food, clothing and footwear, household appliances, goods and services, medical care and health, transport and communications, recreational, educational and cultural services and housing.
} 
Table 2

Descriptive statistics saving rate by survey year and age groups.

\begin{tabular}{llll}
\hline Saving rate by age group & All samples & 1995 & t-Stat \\
\hline $25-29$ & 16.9 & 15.2 & 2002 \\
$30-34$ & 16.6 & 11.6 & 2.04 \\
$35-39$ & 15.7 & 12.6 & 24.1 \\
$40-44$ & 15.0 & 11.0 & 19.3 \\
$45-49$ & 17.7 & 16.9 & 20.2 \\
$50-54$ & 21.4 & 16.7 & 21.5 \\
$55-59$ & 20.5 & 15.2 & 26.4 \\
$60-65$ & 16.3 & 5.11 & 27.1 \\
\hline
\end{tabular}

Notes: The fifth column shows the absolute t-value of a standard test of mean difference across the two surveys. Data source: Chinese Household Income Project (1995, 2002) and authors' calculations.

Table 3

Descriptive statistics of saving rate by public health insurance coverage, survey year and age groups.

\begin{tabular}{|c|c|c|c|c|c|c|}
\hline \multirow[t]{2}{*}{ Saving rate } & \multicolumn{3}{|l|}{1995} & \multicolumn{3}{|l|}{2002} \\
\hline & Coverage & No coverage & t-Stat & Coverage & No coverage & t-Stat \\
\hline All age groups & 13.1 & 13.7 & 0.78 & 23.3 & 19.2 & 4.49 \\
\hline $25-29$ & 14.5 & 16.5 & 0.69 & 22.7 & 18.5 & 0.71 \\
\hline $30-34$ & 10.4 & 14.7 & 2.24 & 23.9 & 24.5 & 0.25 \\
\hline $35-39$ & 12.5 & 12.9 & 0.28 & 20.2 & 17.1 & 1.57 \\
\hline $40-44$ & 11.2 & 10.7 & 0.32 & 21.3 & 17.1 & 2.04 \\
\hline $45-49$ & 12.8 & 13.3 & 0.28 & 22.7 & 18.3 & 2.33 \\
\hline $50-54$ & 15.8 & 16.3 & 0.20 & 27.8 & 21.4 & 2.38 \\
\hline $55-59$ & 16.6 & 17.1 & 0.14 & 28.8 & 21.3 & 1.92 \\
\hline $60-65$ & 16.0 & 13.0 & 0.99 & 24.6 & 24.2 & 0.04 \\
\hline
\end{tabular}

Notes: The fourth and the seventh columns show the absolute t-value of a standard test of mean difference across the two surveys. Data source: Chinese Household Income Project $(1995,2002)$ and authors' calculations.

Another interesting aspect is to explore the evolution of saving rate by type of insurance coverage. In China, the household head can be covered either by public insurance, private insurance, or can remain uninsured. According to the data collected, in the 1995 wave, public insurance was provided by either LIS or GIS, whereas in the 2002 wave it was provided only by BIS. In 1995, 71.12\% of household heads were covered by LIS or GIS, $16.97 \%$ was covered by private health insurance, while the remaining $11.91 \%$ of households heads were not covered by any kind of health insurance. In 2002, 73.63\% of household heads were covered by BIS, $5.32 \%$ was covered by private health insurance while the remaining $21.05 \%$ of households heads were not covered by any kind of health insurance.

Table 3 shows the average saving rate by survey, public health insurance coverage and age groups. It is clear that in 2002 the saving rate is significantly higher for households whose household heads were covered by public health insurance and in the 40-59 age group. No statistically significant differences can be found in 1995 with the only exception of the 30-34 age group. ${ }^{12}$ Fig. 2 shows the saving rate profile by age group and working unit type. We consider two categories of households, those with the household head working in the private sector (employed in a private enterprise) and those with the household head not working in the private sector (therefore working either in public enterprises - State Owned Enterprises (SOE) at central or provincial level or local SOE - or in government agencies or in public institutions). This figure shows that the saving rate pattern is smoother for employees not working in the private sector. Moreover, while in 1995 the saving rate difference for those working in the private sector vs those not working in the private sector was not statistically significant, in 2002 it became significantly higher.

Fig. 3 shows the saving age profile by age group and characteristics of the job contract. In particular, we consider two categories of households, those with the household head permanently employed in a working unit and those without a permanent contract. The figure shows that, in both waves, the saving rate of permanently employed household heads is always higher than the saving rate of the households head with different employment contract.

Finally, descriptive statistics of other relevant variables are reported in Table 4 . We consider the gender and age of the household head, the household composition (number of household members aged less than $25,25-49,50+$ ), the head's years of education and home ownership, and the employment characteristics, including working years in the current work place, permanent employed or not, working in any enterprises or not, type of occupation and economic sectors. The data show that years of education and home

\footnotetext{
12 The data may seem puzzling at first glance but we think there are some clear explanations. First, individuals with health insurance tend to have in average higher propensity to consume health services. The reduction of the generosity of health insurance might have induced these individuals to increase their savings for precautionary reasons. Second, individuals with health insurance have on average also higher income than those without health insurance. Moreover, the difference in income between individuals without coverage and with coverage increased over time, from $21 \%$ in 1995 to $37 \%$ in 2002 . Given that there is a well known relationship between saving rate and household income, the widening of the income differences between the two groups may have contributed to generate the evidence shown in Table 3. Third, we notice that the values reported in Table 3 are simply unconditional mean; as for the case of income, there are other variables correlated with the propensity to save that might have experienced different dynamics in the two groups of individuals (covered and not covered).
} 
Table 4

Descriptive statistics.

\begin{tabular}{|c|c|c|c|}
\hline Variable & 1995 & 2002 & t-Test \\
\hline Gender of head of HH: male & 0.66 & 0.69 & 2.59 \\
\hline Age of head of $\mathrm{HH}$ & 43.60 & 43.45 & 0.81 \\
\hline No. of HH members $0-24$ & 1.03 & 0.88 & 12.95 \\
\hline No. of HH members 25-49 & 1.57 & 1.64 & 4.49 \\
\hline No. of HH members $50+$ & 0.57 & 0.50 & 4.13 \\
\hline Years of education & 10.70 & 11.42 & 11.39 \\
\hline Home ownership & 0.43 & 0.80 & 38.66 \\
\hline Permanent employment & 0.85 & 0.62 & 26.07 \\
\hline Years in current job & 18.13 & 17.42 & 3.58 \\
\hline Employed in enterprise & 0.66 & 0.60 & 5.90 \\
\hline \multicolumn{4}{|l|}{ Occupation dummies } \\
\hline Manager & 0.26 & 0.23 & 2.84 \\
\hline Director of government departments & 0.16 & 0.15 & 1.40 \\
\hline Skilled worker & 0.42 & 0.44 & 1.66 \\
\hline Unskilled worker & 0.16 & 0.18 & 2.44 \\
\hline \multicolumn{4}{|l|}{ Economic sector dummies } \\
\hline Farm, forest and fishery & 0.02 & 0.02 & 1.04 \\
\hline Mineral & 0.41 & 0.29 & 12.29 \\
\hline Manufacturing & 0.01 & 0.03 & 5.35 \\
\hline Electricity, gas, and water supply facilities & 0.03 & 0.04 & 1.06 \\
\hline Construction & 0.06 & 0.12 & 11.16 \\
\hline Geological prospec. and irrigation admin. & 0.13 & 0.07 & 9.03 \\
\hline Transportation, storage, post-office & 0.04 & 0.08 & 9.98 \\
\hline Wholesale, retail, and food services & 0.05 & 0.05 & 1.04 \\
\hline Finance and insurance & 0.08 & 0.10 & 3.55 \\
\hline Real estate & 0.03 & 0.02 & 2.11 \\
\hline Social services & 0.01 & 0.03 & 4.31 \\
\hline Health, sports, and social welfare & 0.13 & 0.14 & 1.82 \\
\hline Education, culture, arts, and mass media & 0.01 & 0.01 & 3.55 \\
\hline
\end{tabular}

Notes: The fourth column shows the absolute t-value of a standard test of mean difference across the two surveys. Data source: Chinese Household Income Project $(1995,2002)$ and authors' calculations.

ownership increased significantly between 1995 and 2002, suggesting a general improvement of the living conditions of the Chinese population. Moreover, significant changes are observed on several indicators of the job position and occupational status. The fraction of employees with permanent employment, the fraction of employees working in enterprises and the job tenure decreased significantly. In addition, in only seven years between 1995 and 2002 the data show significant changes also in the job sector. The fraction of individuals working in the mineral, real estate and geological prospecting and irrigation administration decreased significantly, while increased significantly the fraction of individuals working in the construction, finance and insurance and social services.

\subsection{Empirical results}

As our aim is to estimate the effect of the 1998 health care reform on the saving rate and OOP expenditure, we adopt a simple econometric strategy based on the estimation of the following linear reduced form model:

$$
y_{i, t}=\alpha_{0}+\alpha_{1} P I_{i, t}+\alpha_{2} P R_{i, t}+\alpha_{3} D_{t}+\gamma X_{i, t}+\beta_{1} P I_{i, t} * D_{t}+\beta_{2} P R_{i, t} * D_{t}+\mu_{i, t}
$$

where $y_{i, t}$ is the household $i$ 's saving rate or the ratio between out-of-pocket expenses and disposable income, $P I_{i, t}$ is a dummy variable representing public insurance coverage (it takes value 1 if the household head is covered by LIS or GIS in 1995, or by BIS in 2002, and takes value 0 otherwise), $P R_{i, t}$ is a dummy variable indicating private insurance coverage, $D_{t}$ is the time dummy indicating the prepost reform waves, $X_{i, t}$ is the vector of control variables, which includes household head's demographic characteristics (age and age square), household's composition variables (number of household members divided by age groups), years of education, home ownership and employment characteristics (working unit, permanent vs temporary contract, job tenure, occupation and economic sectors) and the province dummies to take into account geographical heterogeneity. Furthermore, the interaction terms $P I_{i, t} * D_{t}$ and $P R_{i, t} * D_{t}$ should capture the causal effect of the health care reform on outcome variables.

Finally, $\mu_{i, t}$ is the error term and $t$ refers to time (with $t=1995,2002$ ).

The coefficient estimates, obtained through simple OLS regressions, are reported in Table 5. Columns from a to c show the estimated coefficients for OOP expenses-income ratio. Columns from $d$ to $f$ show the estimated coefficients for saving rate. We estimate different model specifications: the first includes only demographic characteristics and province dummies (columns $a$ and $d$ ). The 
Table 5

OLS regressions for out-of-pocket expenses/disposable income ratio and saving rate.

\begin{tabular}{|c|c|c|c|c|c|c|}
\hline \multirow[b]{2}{*}{ Variables } & \multicolumn{3}{|c|}{ OOP expenses-income } & \multicolumn{3}{|l|}{ Saving rate } \\
\hline & (a) & (b) & (c) & (d) & (e) & (f) \\
\hline Public insurance & $\begin{array}{c}-0.005 \\
(0.004)\end{array}$ & $\begin{array}{c}-0.005 \\
(0.004)\end{array}$ & $\underset{(0.004)}{-0.004}$ & $\begin{array}{c}-0.002 \\
(0.011)\end{array}$ & $\begin{array}{c}-0.001 \\
(0.011)\end{array}$ & $\begin{array}{c}-0.006 \\
(0.011)\end{array}$ \\
\hline Private insurance & $\begin{array}{c}-0.002 \\
(0.005)\end{array}$ & $\begin{array}{c}-0.002 \\
(0.005)\end{array}$ & $\underset{(0.005)}{-0.001}$ & $\underset{(0.013)}{-0.004}$ & $\underset{(0.013)}{-0.004}$ & $\begin{array}{c}-0.005 \\
(0.013)\end{array}$ \\
\hline Policy change in 1998 & $\begin{array}{c}0.036^{* * *} \\
(0.005)\end{array}$ & $\begin{array}{l}0.036^{* * *} \\
(0.005)\end{array}$ & $\begin{array}{l}0.035^{* * * *} \\
(0.005)\end{array}$ & $\begin{array}{c}0.047^{* * * *} \\
(0.013)\end{array}$ & $\begin{array}{c}0.039^{* * * *} \\
(0.013)\end{array}$ & $\begin{array}{c}0.048^{* * *} \\
(0.014)\end{array}$ \\
\hline Public Ins.*Policy change in 1998 & $\begin{array}{l}-0.013^{* *} \\
(0.005)\end{array}$ & $\begin{array}{l}-0.013^{* *} \\
(0.005)\end{array}$ & $-\underset{(0.006)}{0.012^{* *}}$ & $\underset{(0.014)}{0.052^{* * * *}}$ & $\begin{array}{c}0.045^{* * * *} \\
(0.015)\end{array}$ & $\begin{array}{c}0.041^{* * * *} \\
(0.015)\end{array}$ \\
\hline Private Ins.*Policy change in 1998 & $\begin{array}{l}-0.020^{* * *} \\
(0.009)\end{array}$ & $\begin{array}{l}-0.020^{* *} \\
(0.009)\end{array}$ & $\begin{array}{l}-0.019^{* *} \\
(0.009)\end{array}$ & $\begin{array}{c}0.039^{*} \\
(0.023)\end{array}$ & $\begin{array}{l}0.033 \\
(0.023)\end{array}$ & $\begin{array}{l}0.027 \\
(0.023)\end{array}$ \\
\hline Gender of head of HH: male & $\begin{array}{l}0.002 \\
(0.002)\end{array}$ & $\begin{array}{l}0.002 \\
(0.002)\end{array}$ & $\begin{array}{l}0.002 \\
(0.002)\end{array}$ & $\begin{array}{l}0.006 \\
(0.006)\end{array}$ & $\begin{array}{l}0.005 \\
(0.006)\end{array}$ & $\begin{array}{l}0.003 \\
(0.006)\end{array}$ \\
\hline Age of head of $\mathrm{HH} / 100$ & $\begin{array}{l}-0.001 \\
(0.016)\end{array}$ & $\begin{array}{l}-0.003 \\
(0.016)\end{array}$ & $\begin{array}{l}0.016 \\
(0.018)\end{array}$ & $\begin{array}{l}0.025 \\
(0.042)\end{array}$ & $\begin{array}{l}0.045 \\
(0.042)\end{array}$ & $\begin{array}{l}0.008 \\
(0.047)\end{array}$ \\
\hline No. of $\mathrm{HH}$ members $0-24$ & $\begin{array}{l}0.003 \\
(0.002)\end{array}$ & $\begin{array}{l}0.003 \\
(0.002)\end{array}$ & $\begin{array}{l}0.003 \\
(0.002)\end{array}$ & $\begin{array}{l}-0.030^{* * *} \\
(0.005)\end{array}$ & $\begin{array}{l}-0.031^{* * *} \\
(0.005)\end{array}$ & $\begin{array}{l}-0.031^{* * *} \\
(0.005)\end{array}$ \\
\hline No. of HH members 25-49 & $\begin{array}{l}0.004^{*} \\
(0.002)\end{array}$ & $\begin{array}{l}0.004^{*} \\
(0.002)\end{array}$ & $\begin{array}{l}0.004^{*} \\
(0.002)\end{array}$ & $\underset{(0.006)}{0.017^{* * * *}}$ & $\begin{array}{l}0.017^{* *} \\
(0.006)\end{array}$ & $\begin{array}{c}0.017^{* * *} \\
(0.006)\end{array}$ \\
\hline No. of $\mathrm{HH}$ members $50+$ & $\begin{array}{c}0.007^{* * * *} \\
(0.002)\end{array}$ & $\begin{array}{c}0.008^{* * * *} \\
(0.002)\end{array}$ & $\begin{array}{c}0.008^{* * * *} \\
(0.002)\end{array}$ & $\begin{array}{c}0.027^{* * * *} \\
(0.005)\end{array}$ & $\begin{array}{c}0.026^{* * * *} \\
(0.005)\end{array}$ & $\frac{0.025^{* * * *}}{(0.005)}$ \\
\hline Education years & - & $\begin{array}{c}-0.000 \\
(0.000)\end{array}$ & $\begin{array}{c}-0.000 \\
(0.000)\end{array}$ & - & $\begin{array}{c}0.002 * * \\
(0.001)\end{array}$ & $\begin{array}{l}0.000 \\
(0.001)\end{array}$ \\
\hline Home ownership & - & $\begin{array}{c}-0.002 \\
(0.002)\end{array}$ & $\begin{array}{c}-0.002 \\
(0.002)\end{array}$ & - & $\begin{array}{c}0.032^{* * * *} \\
(0.006)\end{array}$ & $\begin{array}{c}0.031^{* * * *} \\
(0.006)\end{array}$ \\
\hline Permanent employment & - & - & $\begin{array}{c}-0.002 \\
(0.003)\end{array}$ & - & - & $\begin{array}{c}0.011^{*} \\
(0.011)\end{array}$ \\
\hline Employed in enterprises & - & - & $\begin{array}{c}-0.005 \\
(0.003)\end{array}$ & - & - & $\begin{array}{c}-0.010 \\
(0.009)\end{array}$ \\
\hline Job tenure & - & - & $\begin{array}{c}-0.000 \\
(0.000)\end{array}$ & - & - & $\begin{array}{l}0.000 \\
(0.000)\end{array}$ \\
\hline Occupation dummies & no & no & yes & no & no & yes \\
\hline Economic Sector dummies & no & no & yes & no & no & yes \\
\hline Province dummies & yes & yes & yes & yes & yes & yes \\
\hline Constant & ${ }_{(0.010)}^{0.018^{*}}$ & $\frac{0.022^{*}}{(0.011)}$ & $\begin{array}{l}0.026^{*} \\
(0.014)\end{array}$ & $\begin{array}{c}0.082^{*} * * * * \\
(0.027)\end{array}$ & $\begin{array}{l}0.047 \\
(0.030)\end{array}$ & $\begin{array}{c}0.074^{* *} * \\
\end{array}$ \\
\hline Observations & 9499 & 9499 & 9499 & 9499 & 9499 & 9499 \\
\hline
\end{tabular}

Notes: ${ }^{* * *}$ significance at $1 \%$ level, ${ }^{* *}$ significance at $5 \%$ level, and ${ }^{*}$ significance at $10 \%$ level. See Table 4 for the occupation dummies and the economic sector dummies included in the regressions. Data source: Chinese Household Income Project $(1995,2002)$.

second adds years of education and home ownership (columns $b$ and $e$ ). Finally, the third specification, the most complete, adds the job characteristics of the household head (columns $\mathrm{c}$ and $\mathrm{f}$ ). ${ }^{13}$

According to these results, the effect of the health care reform on the OOP expenses-income ratio (columns a-c) is negative and statistically significant. Furthermore, we find that the interaction effect with survey year is negative and larger for those who are covered by private insurance, although the difference is not statistically significant. These results suggest that after the reform, OOP expenses have increased, but both public insurance and private insurance prove to serve as a cushion against health risks, given that they do seem to reduce the OOP expenses-income ratio. Furthermore, we find that a larger number of household members aged $25+$ significantly increases the OOP expenses-income ratio. Moreover, years of education and the employment characteristics do not play any role.

Looking at the saving rate model (columns d-f), the results are in line with those obtained for the OOP expenses-income ratio. In this case we find that the interaction term between public insurance coverage and post-reform dummy is positive and statistically significant at $1 \%$ and this result is robust across model specifications. This suggests that the health care reform had an effect on saving rate for those individuals covered by public health insurance or, put differently, that the public coverage induces households to save between 4.1 and 5.2 percentage points more than households not covered by any kind of health insurance.

As already mentioned in Section 3.1, our measures of saving rate and out-of-pocket expenditure may be biased if individuals tend to under-report expenditure consumption and reimbursement and if this under-reporting is heterogeneous across the sample. Following the evidence found by Cifaldi and Neri (2013), to address this point we re-estimate the most complete specification by income tertile, as income may constitute a potential source of heterogeneity in the under-reporting of consumption and reimbursement. Table 6 shows the results by income tertiles.

Controlling for income tertiles, the results obtained provide a different picture. As far as the results for OOP expenses-income ratio are concerned, we find that the reform of the public health insurance did not affect the OOP expenses-income ratio (the coefficient of the interaction effect between health insurance and the policy change dummy is never statistically significant). As far as the results for saving rate are concerned, we find significant effects of the public health coverage only in the first tertile. Indeed, the coefficient of the public insurance coverage is negative and statistically significant, while the coefficient of the interaction term between public

\footnotetext{
${ }^{13}$ We estimate different model specifications to check whether there are variables driving the effect on OOP expenses-income ratio and saving rate. However, since the coefficients of the key variables do not change between model specifications, we can conclude that this concern is unfounded.
} 
Table 6

OLS regressions for out-of-pocket expenses/disposable income ratio and saving rate by income tertiles.

\begin{tabular}{|c|c|c|c|c|c|c|}
\hline \multirow[b]{2}{*}{ Variables } & \multicolumn{3}{|c|}{ OOP expenses-income } & \multicolumn{3}{|l|}{ Saving rate } \\
\hline & 1st Ter & 2nd Ter & 3rd Ter & 1 st Ter & 2nd Ter & 3rd Ter \\
\hline Public insurance & $\underset{(0.004)}{-0.001}$ & $\begin{array}{c}-0.002 \\
(0.011)\end{array}$ & $\underset{(0.016)}{-0.009}$ & $-0.041^{* * *}$ & $\begin{array}{l}-0.026 \\
(0.023)\end{array}$ & $\underset{(0.043)}{-0.013}$ \\
\hline Private insurance & $\begin{array}{c}-0.003 \\
(0.005)\end{array}$ & $\begin{array}{l}0.008 \\
(0.012)\end{array}$ & $\underset{(0.017)}{-0.004}$ & $\underset{(0.016)}{-0.020}$ & $-\underset{(0.026)}{0.019}$ & $-\underset{(0.046)}{-0.038}$ \\
\hline Policy change in 1998 & $\begin{array}{c}0.038^{* * *} \\
(0.006)\end{array}$ & $\begin{array}{c}0.049^{* * * *} \\
(0.013)\end{array}$ & ${ }_{(0.016)}^{0.027^{*}}$ & $\begin{array}{c}0.009 \\
(0.018\end{array}$ & $\frac{-0.005}{(0.026)}$ & $\begin{array}{l}0.018 \\
(0.045)\end{array}$ \\
\hline Public Ins.*Policy change in 1998 & $\begin{array}{c}-0.009 \\
(0.007)\end{array}$ & $-\underset{(0.013)}{0.015}$ & $\begin{array}{l}0.005 \\
(0.017)\end{array}$ & $\begin{array}{c}0.064^{* * *} \\
(0.023)\end{array}$ & $\begin{array}{l}0.013 \\
(0.028)\end{array}$ & $\begin{array}{l}0.021 \\
(0.045)\end{array}$ \\
\hline Private Ins. ${ }^{*}$ Policy change in 1998 & $-{ }_{(0.015)}^{0.031^{* *}}$ & $\begin{array}{c}-0.017 \\
(0.020)\end{array}$ & $\begin{array}{c}-0.006 \\
(0.020)\end{array}$ & $\begin{array}{c}-0.002 \\
(0.049)\end{array}$ & $\begin{array}{c}-0.009 \\
(0.042)\end{array}$ & $\begin{array}{l}0.053 \\
(0.054)\end{array}$ \\
\hline Gender of head of $\mathrm{HH}$ : male & ${ }_{(0.003)}^{0.005^{*}}$ & $\begin{array}{l}0.001 \\
(0.005)\end{array}$ & $\underset{(0.004)}{-0.004}$ & $\begin{array}{l}0.011 \\
(0.010)\end{array}$ & ${ }_{(0.010)}^{0.018^{*}}$ & $\begin{array}{l}0.007 \\
(0.010)\end{array}$ \\
\hline Age of head of $\mathrm{HH} / 100$ & $\begin{array}{l}0.002 \\
(0.024)\end{array}$ & $\begin{array}{l}0.013 \\
(0.038)\end{array}$ & $\frac{0.062^{* *}}{(0.031)}$ & $\begin{array}{c}-0.081 \\
(0.079)\end{array}$ & $\begin{array}{c}-0.126 \\
(0.080)\end{array}$ & $\begin{array}{l}0.071 \\
(0.085)\end{array}$ \\
\hline No. of $\mathrm{HH}$ members $0-24$ & $\begin{array}{l}0.001 \\
(0.003)\end{array}$ & $\underset{(0.004)}{0.004}$ & $\underset{(0.003)}{0.006^{*}}$ & $\begin{array}{c}-0.026^{\text {**** }} \\
(0.008)\end{array}$ & $-{ }^{-0.038^{* * * *}}$ & $-{ }_{(0.009)}^{0.049^{* * *}}$ \\
\hline No. of HH members $25-49$ & $\begin{array}{c}0.006^{*} \\
(0.003)\end{array}$ & ${ }_{(0.005)}^{0.011^{* *}}$ & $\begin{array}{l}0.005 \\
(0.004)\end{array}$ & $\begin{array}{l}0.012 \\
(0.011)\end{array}$ & $-{ }_{(0.010)}^{0.019}$ & $\begin{array}{c}-0.004 \\
(0.010)\end{array}$ \\
\hline No. of $\mathrm{HH}$ members $50+$ & $\begin{array}{c}0.012^{* * *} \\
(0.003)\end{array}$ & $\frac{0.014^{* * * *}}{(0.005)}$ & $\frac{0.007^{* *}}{(0.003)}$ & ${ }_{(0.011)}^{0.019^{*}}$ & $\underset{(0.010)}{-0.004}$ & $\begin{array}{l}0.007 \\
(0.008)\end{array}$ \\
\hline Education years & $\begin{array}{l}0.001 \\
(0.001)\end{array}$ & $\begin{array}{l}0.001 \\
(0.001)\end{array}$ & $\begin{array}{l}0.000 \\
(0.001)\end{array}$ & $\begin{array}{l}0.000 \\
(0.002)\end{array}$ & $\underset{(0.002)}{-0.001}$ & $\begin{array}{c}-0.006^{* * * *} \\
(0.002)\end{array}$ \\
\hline Home ownership & $\begin{array}{c}-0.003 \\
(0.003)\end{array}$ & $\underset{(0.005)}{-0.001}$ & $-\underset{(0.004)}{0.000}$ & $\begin{array}{l}0.000 \\
(0.009)\end{array}$ & $\underset{(0.010)}{0.050^{* * * *}}$ & $\begin{array}{c}0.030^{* *} \\
(0.012)\end{array}$ \\
\hline Permanent employment & $\begin{array}{l}0.001 \\
(0.003)\end{array}$ & $\begin{array}{c}-0.007 \\
(0.005)\end{array}$ & $\begin{array}{l}0.003 \\
(0.004)\end{array}$ & $\begin{array}{l}0.005 \\
(0.011)\end{array}$ & $\begin{array}{l}0.008 \\
(0.011)\end{array}$ & $\begin{array}{l}0.019 \\
(0.012)\end{array}$ \\
\hline Employed in enterprises & $\frac{-0.002}{(0.005)}$ & $\underset{(0.007)}{-0.010}$ & $\begin{array}{c}-0.001 \\
(0.005)\end{array}$ & $\underset{(0.016)}{-0.006}$ & $\begin{array}{l}0.015 \\
(0.014)\end{array}$ & $-0.028^{*}$ \\
\hline Job tenure & $\begin{array}{c}-0.000 \\
(0.000)\end{array}$ & $\begin{array}{c}-0.000 \\
(0.000)\end{array}$ & $\begin{array}{c}-0.000 \\
(0.000)\end{array}$ & $\begin{array}{l}0.001 \\
(0.001)\end{array}$ & $\begin{array}{l}0.001 \\
(0.001)\end{array}$ & $\underset{(0.001)}{-0.001}$ \\
\hline Occupation dummies & yes & yes & yes & yes & yes & yes \\
\hline Economic Sector dummies & yes & yes & yes & yes & yes & yes \\
\hline Province dummies & yes & yes & yes & yes & yes & yes \\
\hline Constant & $\frac{0.074^{* * * *}}{(0.023)}$ & $\begin{array}{l}0.036 \\
(0.035)\end{array}$ & $\begin{array}{c}-0.033 \\
(0.031)\end{array}$ & $\begin{array}{c}-0.038 \\
(0.076)\end{array}$ & $\underset{(0.073)}{0.399^{* * * *}}$ & $\frac{0.357^{\text {**** }}}{(0.085)}$ \\
\hline Observations & 3167 & 3166 & 3166 & 3167 & 3166 & 3166 \\
\hline
\end{tabular}

Notes: ${ }^{* * *}$ significance at $1 \%$ level, ${ }^{* *}$ significance at $5 \%$ level, and ${ }^{*}$ significance at $10 \%$ level. See Table 4 for the occupation dummies and the economic sector dummies included in the regressions. Data source: Chinese Household Income Project $(1995,2002)$.

insurance coverage and the policy change dummy is positive and statistically significant, suggesting that after the health care reform low income households with a public insurance save significantly more compared to those not covered.

\subsection{Data limitations: dealing with the unobserved heterogeneity}

Although the analysis carried out so far presents some interesting policy results, we are aware of the existence of limitations in our data that may strongly influence the estimates. In particular, our dataset lacks information on individual health status and both OOP expenses and saving rate are likely to be affected by the individual health status. Therefore, if the health status is an important determinant of outcomes, this will lead to the existence of some forms of unobserved heterogeneity and our current estimate of the health insurance coverage effect could, at best, be interpreted as an average effect across individuals with poor and good health. ${ }^{14}$

Indeed, evidence of the existence of some unobserved heterogeneity may be seen in Figs. 3 and 4. These figures are kernel density estimates of the distribution of OLS residuals from our models in Eq. (1). To take into account such unobserved heterogeneity, we estimate a finite mixture model. Finite Mixture Models (FMMs) are semi-parametric estimators that have received increasing attention both in the economics and statistics literature because there are different areas in which such distributions are encountered. The FMMs provide a natural representation of heterogeneity in a finite number of latent classes. It concerns modeling any statistical distribution by a mixture of other distributions. ${ }^{15}$

Following Deb and Trivedi (1997), the density function for a C-component finite mixture is

$$
f\left(y \mid \mathbf{x} ; \theta_{1}, \theta_{2}, \ldots, \theta_{C} ; \pi_{1}, \pi_{2}, \ldots, \pi_{C}\right)=\sum_{j=1}^{C} \pi_{j} f_{j}\left(h \mid \mathbf{x} ; \theta_{j}\right)
$$

\footnotetext{
${ }^{14}$ What is available in the dataset is the number of sick leave days taken in the current year in 1995 and a measure of self-perceived health status in 2002 . These two pieces of information are not directly comparable to obtain a synthetic and coherent measure of health status variation across the two waves. Theoretically, we could have constructed a coherent health status index based on the distribution of the answers to both questions. However, the large number of missing values for the number of sick leave days makes this strategy useless as it would drastically reduce the sample size for the analysis.

${ }^{15}$ Atella and Deb (2013) provide a review of the contributions adopting the Finite Mixture approach.
} 
where $0<\pi_{j}<1$, and $\sum_{j=1}^{C} \pi_{j}=1$ and $f_{j}$ denotes an appropriate density given the characteristics of the error terms. In this contest normally distributed components appear to be appropriate in the context of the outcome of interest. We estimate the model's parameters using maximum likelihood. In addition, in post-estimation, we calculate the posterior probability that observation $y_{i}$ belongs to component $c$ (the prior probability is assumed to be a constant):

$$
\operatorname{Pr}\left[y_{i} \in \text { population } c \mid \mathbf{x}_{i}, y_{i} ; \theta\right]=\frac{\pi_{C} f_{C}\left(y_{i} \mid \mathbf{x}_{i}, \theta_{C}\right)}{\sum_{j=1}^{C} \pi_{j} f_{j}\left(y_{i} \mid \mathbf{x}_{i}, \theta_{j}\right)}, \quad c=1,2, . . C
$$

which we use to explore the determinants of class membership, and especially to see if these determinants are consistent with the idea that health status is the likely source of unobserved heterogeneity.

By mean of the Akaike Information Criterion and Bayesian Information Criterion we select a two class FMM. Parameter estimates of the finite mixture model by income tertiles for OOP expenses-income ratio (columns a and b) and saving rate (columns c and d) are reported in Table 7. Differently from OLS estimates, our findings suggest that, accounting for some forms of unobserved heterogeneity (potentially induced by health status), out-of-pocket expenses and saving rate are affected by the reform in a differentiated way. In particular, we find that the ratio between out-of-pocket expenses and income increases more for individuals belonging to the first class compared to those in the second class, for all income tertiles. On the contrary, the saving rate increases only for class 1 individuals in the first tertile and only for class 2 individuals in the third tertile.

Furthermore, we find that, after the reform of the public insurance, only class 2 individuals with high income (in the third tertile) have been cushioned against the increase in out-of-pocket expenses. On the contrary, in the case of the saving rate we find significant effects only for low income individuals (in the first tertile) in class 2.

These results support the prima facie evidence that the estimated class probabilities are informative vis-à-vis our speculative hypothesis that the distributions are drawn from individuals with poor health and good health, with the evidence suggesting that component 1 represents individuals with poor health. The posterior probabilities seem to support our hypothesis: in the model for

Table 7

ML regressions for out-of-pocket expenses/disposable income ratio and saving rate by income tertiles.

\begin{tabular}{|c|c|c|c|c|}
\hline \multirow[b]{2}{*}{ First income tertile } & \multicolumn{2}{|c|}{ OOP expenses-income } & \multicolumn{2}{|l|}{ Saving rate } \\
\hline & $\begin{array}{l}\text { Comp: } 1 \\
\text { (a) }\end{array}$ & $\begin{array}{l}\text { Comp: } 2 \\
\text { (b) }\end{array}$ & $\begin{array}{l}\text { Comp: } 1 \\
\text { (c) }\end{array}$ & $\begin{array}{l}\text { Comp: } 2 \\
\text { (d) }\end{array}$ \\
\hline Public insurance & -0.010 & -0.002 & $-0.025^{* *}$ & $-0.96^{*}$ \\
\hline Private insurance & -0.028 & -0.001 & -0.023 & 0.011 \\
\hline Policy change in 1998 & $0.069^{* * *}$ & $0.009^{* * *}$ & $0.057^{* * *}$ & $-0.147^{* *}$ \\
\hline Public Ins.*Policy change in 1998 & -0.009 & -0.000 & 0.022 & $0.229^{* *}$ \\
\hline Private Ins. Policy change in 1998 & -0.064 & $-0.008^{*}$ & $0.105^{* *}$ & -0.035 \\
\hline$\sigma$ & 0.127 & 0.018 & 0.323 & 0.153 \\
\hline$\pi$ & 0.173 & 0.827 & 0.212 & 0.788 \\
\hline Second income tertile & $\begin{array}{l}\text { Comp: } 1 \\
\text { (a) }\end{array}$ & $\begin{array}{l}\text { Comp: } 2 \\
\text { (b) }\end{array}$ & $\begin{array}{l}\text { Comp: } 1 \\
\text { (c) }\end{array}$ & $\begin{array}{l}\text { Comp: } 2 \\
\text { (d) }\end{array}$ \\
\hline Public insurance & 0.021 & -0.003 & -0.110 & -0.010 \\
\hline Private insurance & 0.026 & -0.000 & 0.123 & $-0.039^{*}$ \\
\hline Policy change in 1998 & $0.154^{*}$ & $0.010^{* * *}$ & -0.105 & 0.004 \\
\hline Public Ins.*Policy change in 1998 & -0.097 & -0.000 & 0.085 & 0.011 \\
\hline Private Ins.*Policy change in 1998 & -0.116 & -0.001 & -0.127 & 0.011 \\
\hline$\sigma$ & 0.255 & 0.017 & 0.171 & 0.309 \\
\hline$\pi$ & 0.139 & 0.861 & 0.133 & 0.867 \\
\hline Third income tertile & $\begin{array}{l}\text { Comp: } 1 \\
\text { (a) }\end{array}$ & $\begin{array}{l}\text { Comp: } 2 \\
\text { (b) }\end{array}$ & $\begin{array}{l}\text { Comp: } 1 \\
\text { (c) }\end{array}$ & $\begin{array}{l}\text { Comp: } 2 \\
\text { (d) }\end{array}$ \\
\hline Public insurance & 0.062 & $0.101^{* * *}$ & -0.149 & 0.032 \\
\hline Private insurance & 0.076 & $0.103^{* * *}$ & -0.224 & 0.013 \\
\hline Policy change in 1998 & $0.165^{* * *}$ & $0.112^{* * *}$ & -0.204 & $0.077^{*}$ \\
\hline Public Ins.*Policy change in 1998 & -0.053 & $-0.105^{* * *}$ & 0.189 & -0.035 \\
\hline Private Ins.*Policy change in 1998 & -0.100 & -0.105 & 0.299 & -0.021 \\
\hline$\sigma$ & 0.186 & 0.014 & 0.175 & 0.333 \\
\hline$\pi$ & 0.173 & 0.827 & 0.204 & 0.796 \\
\hline
\end{tabular}

Notes: $^{* * *}$ significance at $1 \%$ level, ${ }^{* *}$ significance at $5 \%$ level, and ${ }^{*}$ significance at $10 \%$ level.

The regressions include the same set of regressors as Table 5, columns c and f. Data source: Chinese Household Income Project (1995, 2002). 
OOP expenses-income ratio the probability of being in component 1 are 17.3, 12.5, and 17.3\% (respectively for the first, second and third income tertiles), while in the saving rate equation the same probabilities are $21.0,13.3$, and $20.4 \%$.

Although we have not been able to obtain information on the health distribution for a population that is perfectly overlapping with our population, we feel comfortable to claim that the posterior probabilities are consistent with some recent findings on health status distribution available in the literature (Chatterji et al., 2008; Mu, 2013; Strauss et al., 2011; Zhao, 2008). In particular, according to Zhao (2008) $26.0 \%$ of the whole sample reported a poor and fair health status ranging from $34.8 \%$ in the Hubei province and $13.4 \%$ in Heilongjiang. Chatterji et al. (2008) show that $16.0 \%$ of the respondents in China reported having at least one chronic disease. Strauss et al. (2011) find that $22.0 \%$ of women and 30.0\% of men reported poor general health. Finally, Mu (2013) finds that $24.0 \%$ of the sample self-reports a poor health status. Given that our sample is younger than the samples used by the authors listed above, we can reasonably infer that class 1 represents the group of individuals with poor health.

To better characterize class membership, for both OOP expenses-income ratio and saving rate we run OLS regressions of the posterior probabilities (multiplied by 100) of belonging to class 1 on a set of variables including age, sex, years of education and a set of job characteristics (working unit, type of contract). The results presented in Table 8 support the poor health/good health categorization. In both equations the coefficients of age is positive and statistically significant, suggesting, as expected, that aging is associated with the worsening of health status. Moreover, the coefficients of working in an enterprise and with permanent employment contract are negative, suggesting that poorer families with household head employed with temporary contract are more likely to have a poor general health with respect to wealthier families with household head employed with a permanent contract and working in an enterprise.

We conclude this section by comparing our findings with previous evidence on the effects achieved by the reform in terms of reduction of out-of-pocket expenditures. Existing evidence in the literature is still mixed and contradictory. Several studies document that out-of-pocket expenses increased as a consequence of the reform. Among the others, Liu and Zhao (2006), using data from the pilot experiment conducted in Zhenjiang, found that the introduction of the BIS led to an increase in out-of-pocket payments. Nevertheless, redistributions in out-of-pocket payments appear to favor disadvantaged groups, suggesting more equitable cost-sharing within BIS. Yip and Hsiao (2009), using data from the National Health Survey, reports that the out-of-pocket expenses associated with a single inpatient admission increased from 70 to $80 \%$ of per capita income in 1993 to more than $200 \%$ in 2003. Using data from three different household surveys spanning the period 1991-2004 and covering half of China's 32 provinces, Wagstaff and Lindelow (2008) found that the insurance reform typically increased expected out-of-pocket payments and the risk of large out-of-pocket payments. This occurs because insurance may encourage the use of higher-level providers, which in turn may lead to higher out-of-pocket spending. On the contrary, Liu et al. (2008) found that the incidence of catastrophic payments (defined as health spending exceeding $30 \%$ of capacity to pay) fell in urban areas between 1998 and 2003. Nevertheless, their results suggest that people with low income have an increased probability of undergoing catastrophic medical spending.

Our findings contribute to this debate. Analyzing the results achieved by the reform in terms of reduction of out-of-pocket expenditure by income levels and controlling for potential unobserved heterogeneity due to health status, we find that the coefficient of the interaction term between public health insurance and policy change dummy is negative and statistically significant only for high income households (the third tertile) and only for individuals belonging to the second group, i.e. those in good health status. Actually, this result is worrisome, as it suggests that the public health coverage after the reform provides financial protection only to individuals that are relatively better off (with good health status and high income).

\subsection{Other limitations of the study}

In this paper we focus on the 1998 health care system reform and we analyze a pre- and post-reform (the CHIP 1995 and 2002 waves). However, during the period 1995-2002, changes in other policies occurred as well, both in the welfare system and in the access of households to real and financial asset markets (e.g. housing market). All these reforms can affect the wellbeing of the urban residents and lead to changes in their expenditures and savings. Unfortunately these confounding factors may not be easily controlled for in our empirical analysis. Nevertheless, it is important to highlight how also the other reforms might have contributed to changes of the household saving, together with that in the health sector. For this reason, in this section we present the key aspects of the pension system and the housing market reforms.

Table 8

OLS estimates of the correlates of the posterior probabilities.

\begin{tabular}{|c|c|c|c|c|c|c|}
\hline \multirow[b]{2}{*}{ Variables } & \multicolumn{3}{|c|}{ OOP expenses-income } & \multicolumn{3}{|l|}{ Saving rate } \\
\hline & 1st Ter & 2nd Ter & 3rd Ter & 1st Ter & 2nd Ter & 3rd Ter \\
\hline Gender of head of $\mathrm{HH}$ : male & 1.518 & 0.484 & -0.746 & 1.489 & 0.039 & -0.869 \\
\hline Age & $0.144^{* *}$ & $0.169^{* *}$ & $0.271^{* *}$ & $0.109^{* *}$ & $0.069^{*}$ & -0.011 \\
\hline Education years & -0.106 & -0.162 & -0.034 & 0.050 & -0.011 & -0.000 \\
\hline Permanent employment & $-4.152^{* * *}$ & $-3.736^{* * *}$ & $-6.133^{* * *}$ & $-0.956^{*}$ & 0.621 & 0.505 \\
\hline Employed in enterprise & -1.929 & 1.576 & -0.449 & $-1.686^{*}$ & 0.987 & 0.930 \\
\hline
\end{tabular}

Notes: $^{* * *}$ significance at $1 \%$ level, ${ }^{* *}$ significance at 5 \% level, and ${ }^{*}$ significance at 10 \% level. Data source: Chinese Household Income Project (1995, 2002). 
It is important to take into account the former because, in a life-cycle-theory framework, the provision of public pensions may substitute for private saving, hence it is essential to look at the social security provisions and welfare reforms to disentangle the different motives for saving.

China's national urban pension system was put in place in 1951 and it was initially based uniquely on the employer contributions. The system was Pay As You Go (PAYG) and replaced about 75-90\% of the employee's wage. This enterprise-based system lasted until the mid-1990s, when the burden on companies became too large. In 1997 the Chinese Government launched a major reform establishing a three pillars pension system. The first pillar consists on a payroll tax on the employer of $17 \%$ such that workers with 15 years of contributions had a replacement rate of $20 \%$. The second pillar is based on both employer's and employee's contributions ( $11 \%$ total contribution of which $3 \%$ paid by the employer while the rest is paid by the employee). The third pillar consists on voluntary contributions.

The reform also introduces gradual changes on the benefit provision according to seniority: i) individuals retired before 1997 (the so called "old workers") would receive benefits according to the old PAYG regime; ii) those who have not yet retired but working before 1997 ("middle workers") were in a transitional plan with rules based on a pro-rata system; individuals who started work after 1997 (the so called "new workers"), who would be under the three pillars regime (Herd, Hu, \& Koen, 2010; Impavido, Hu, \& Li, 2009; OECD, 2010). According to the reform, the "old workers" had a very generous treatment with respect to the "new workers" as no contributions were required from the employee and replacement rates were very high. In the same period, many large-scale SOEs provided immediate pensions to laid-off workers even at quite young ages.

To take into account the potential effect of the pension reform on saving, we estimated Eq. (1) by cohort. We divided the sample into three cohorts (born between 1937 and 1948, 1949 and 1959, 1960 and 1970) and we run three different regressions, considering the most complete specification. The results, not shown but available upon request, show that the effect of the public health insurance on household saving is positive and statistical significant for the youngest and oldest cohorts, while is not significant for the second cohort (household heads born between 1949 and 1959).

Another major reform that may have affected the household saving is the reform of the housing market, which began in 1980 and completely transformed a centrally planned public housing system into a market-oriented housing industry. Before the reform, housing was treated as a component of social welfare and was provided mostly for free by government institutions and SOEs. The first stage of the housing reform started in 1980 and in 1988 the central government established a nationwide housing market: the public housing units throughout the country started to be sold to their sitting tenant at heavily discounted prices. The second stage of the housing reform started in 1994 with the issue of a regulatory document which established a comprehensive framework to facilitate the development of both supply side and demand side of the housing market. On the supply side, the government decided to build a multi-layer housing provision system for different income groups. On the demand side, a dual housing finance system was established to combine both social saving and private saving (Wang \& Murie, 2000). Potential home buyers could apply for commercial mortgage loans offered by financial institutions and for subsidized mortgage loans through a housing saving program called Housing Provident Fund (HPF). This program was formally mandatory for Government agency, public institutions, SOEs, urban collective enterprises, foreign-invested enterprises, urban private enterprises and other urban enterprises, but in 2002 only about $60 \%$ of employees actually joined the program. Within the HPF program, both the employer and employee contribute a certain percentage of the employees' salaries (between $4 \%$ and $10 \%$ ) to an individual account. This program combines a $401(\mathrm{k})$-like savings and retirement account with subsidized mortgage rates and price discounts to provide a mechanism through which an employee could save for a housing purchase (Buttimer, Gu, \& Yang, 2004). Intuitively, the HPF program might have a twofold effect on household saving. On the one hand, it could have an indirect effect through its impact on the decision to own a house or on the intention to purchase a house in the future. On the other hand, it might have a direct effect on saving, and the sign of the effect could be in principle both positive and negative. Indeed, the HPF might work as an alternative source of finance because it allows to access loans with a low interest rate. In this case, the effects of HPF on saving are negative. At the contrary, HPF might also work as a way to motivate the accumulation of financial sources to purchase houses. In this case, the effects of HPF on saving are positive.

To take into account the potential effect of the housing reform on saving, we estimated Eq. (1) by adding a dummy variable for participation to the program of any household member and its interaction with survey year. The results, not shown but available upon request, show that the effect of the public health insurance on household saving is robust to the inclusion of these additional controls.

\section{Conclusion}

In this paper we have analyzed the economic effects of the third stage of the health care system reform occurred in 1998, when the Chinese government established a new public insurance scheme, called the Basic Insurance Scheme (BIS) nationwide. In particular, we have focused on the effects produced on OOP expenses and household's saving rate.

Using data from the 1995 and 2002 waves of the Chinese Household Income Project Survey for the Chinese urban households, we have estimated an empirical model to explore the effect of the 1998 reform. According to a first set of results based on OLS technique, the reform has negatively affected OOP expenses and positively affected saving rate. Furthermore, this first set of results suggest that both public insurance and private insurance prove to serve as a cushion against health risks, given that they do seem to reduce the ratio of OOP expenses compared to disposable income.

As these results may be biased due to the presence of self-selection in the adoption of insurance schemes and to unobserved heterogeneity related to health status, we use a Finite Mixture Model on population subsamples according to income tertiles. In 
this way we are able to isolate, by income tertiles, two distinct groups that, according to posterior probability regression estimates, could be associated with "bad" and "good" health status. Once properly accounted for this form of heterogeneity and for selfselection, the effects of the reform are quite different. In particular, we find that after the reform out-of-pocket expenses decrease only for individuals with good health status at the top of the income distribution (the less vulnerable) and the saving rate increases only for individuals with good health status at the bottom of the income distribution.

Overall, our results are somewhat surprising if compared with the standard literature developed for Western economies. Once attention is paid to the income distribution and to the different populations reflected in the sample vis-à-vis the different health characteristics, the role of public health provisions in protecting against current and future health shocks almost disappears. We cannot say much about the specific reason for this failure, but a possible explanation is the reduced coverage for dependent household members (spouse and children of the employee).

\section{Appendix A}

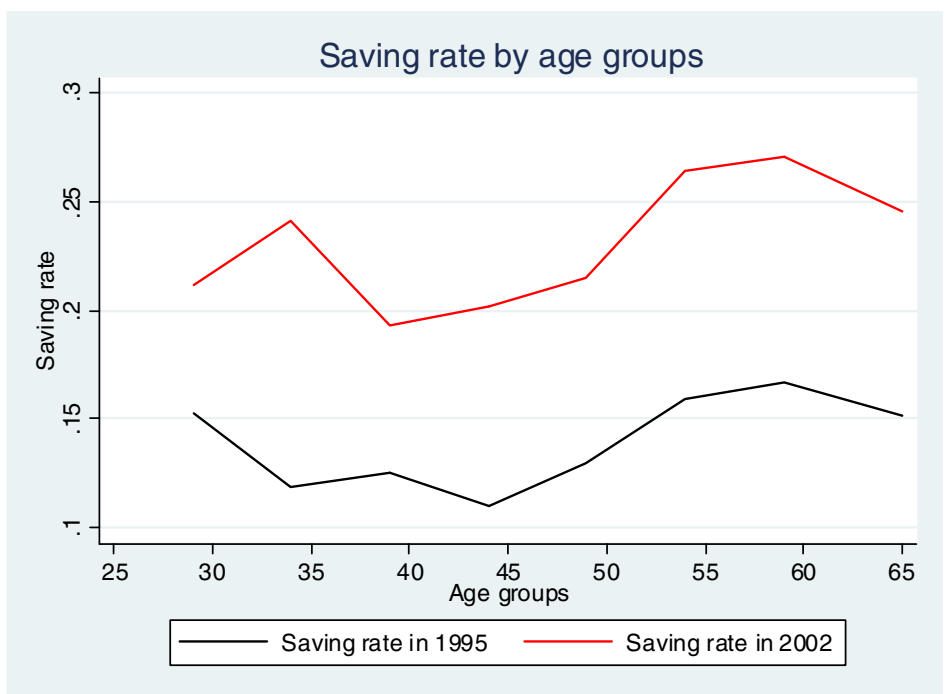

Fig. 1. Saving rate by age groups and survey year. Data source: Chinese Household Income Project $(1995,2002)$

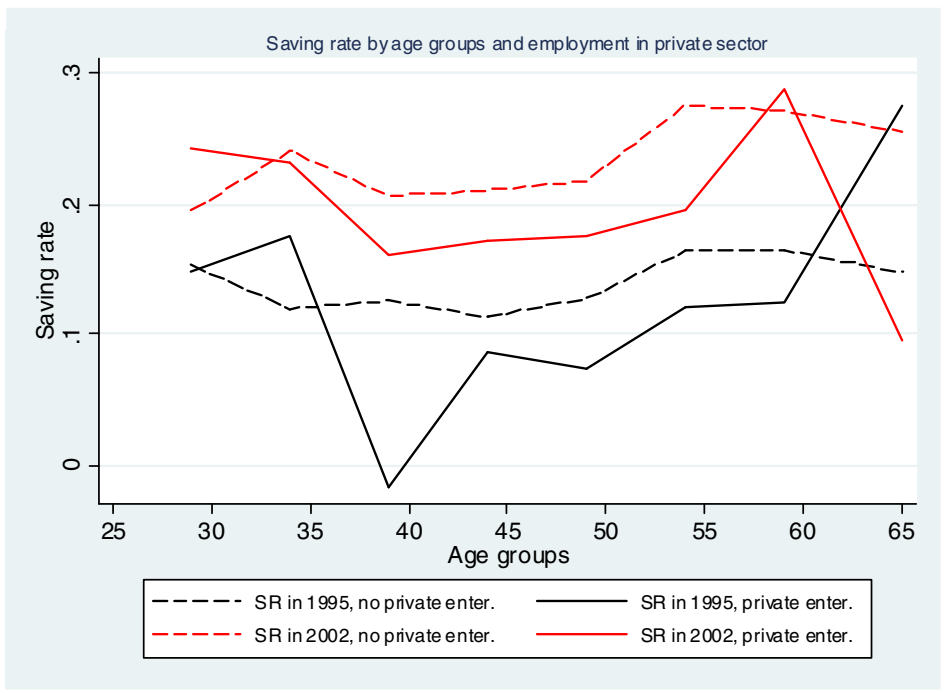

Fig. 2. Saving rate by age groups, private/not private enterprise and survey year. Data source: Chinese Household Income Project $(1995,2002)$ 


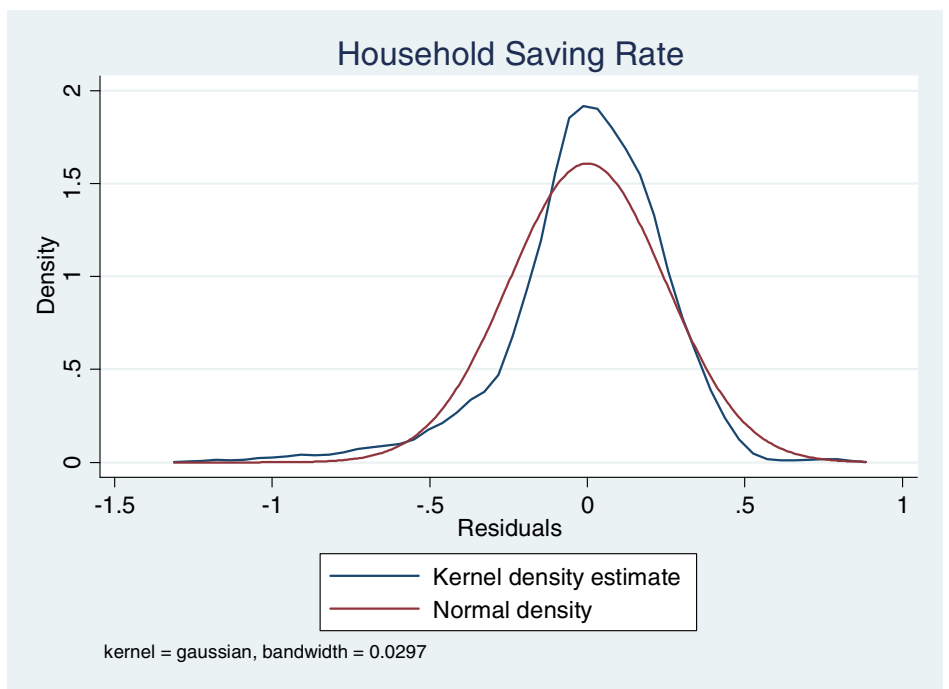

Fig. 3. Kernel density of OLS residuals of saving rate. Data source: Chinese Household Income Project $(1995,2002)$

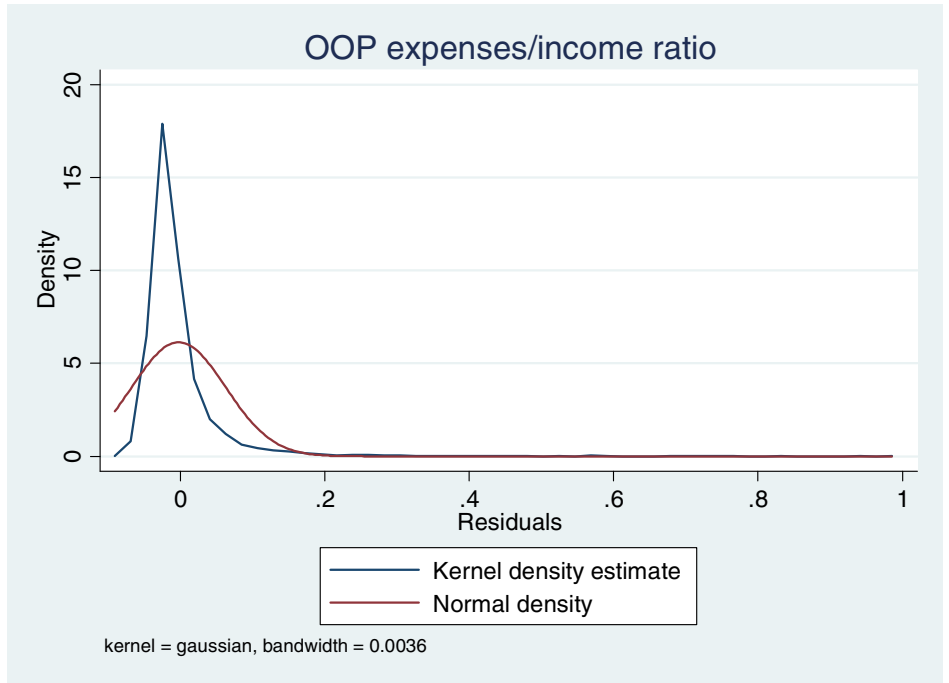

Fig. 4. Kernel density of OLS residuals of OOP/income.

Data source: Chinese Household Income Project $(1995,2002)$

\section{References}

Aaberge, R., \& Zhu, Y. (2001). The pattern of household savings during a hyperinflation: The case of urban China in the late 1980s. Review of Income and Wealth, 47, $181-202$.

Atella, V., Brugiavini, A., Chen, H., \& Pace, N. (2014). The Chinese health care system reforms and household saving patterns: Some stylized facts. In Taylor (Eds.), The globalisation of Chinese business; implications for multinational investors. Oxford: Chandos publishing.

Atella, V., \& Deb, P. (2013). Heterogeneity in long term health outcomes of migrants within Italy. NBER working paper No. 19422.

Attanasio, O., Battistin, E., \& Ichimura, H. (2004). What really happened to consumption in-equality in the US? Working paper 10338. National Bureau of Economic Research.

Attanasio, O., \& Weber, G. (2010). Consumption and saving: Models of intertemporal allocation and their implications for public policy. Journal of Economic Literature, 48(3), 693-751.

Baldacci, E., Callegari, G., Coady, D., Ding, D., Kumar, M., Tommasino, P., et al. (2010). Public expenditures on social programs and household consumption in China. IMF Working Paper 10/69.

Barnett, S., \& Brooks, R. (2010). China: Does government health and education spending boost consumption? IMF Working Paper 10/16.

Battistin, E. (2003). Errors in survey reports of consumption expenditures. IFS working papers W03/07. Institute for Fiscal Studies.

Brown, P., De Brauw, A., \& Yang, D.D. (2009). Understanding variation in the design of China's new co-operative medical system. China Quarterly, 198, 304-329.

Brugiavini, A., Weber, G., \& Wu, B. (2013). Saving rates of urban households in China. In G. Gomel (Eds.), The Chinese economy. Berlin Heidelberg: Springer-Verlag. Buttimer, R., Gu, A.Y., \& Yang, T. (2004). The Chinese housing provident fund. International Real Estate Review, 7, 1-30. 
Carrin, G., Ron, A., Hui, Y., Hong, W., Tuohong, Z., Licheng, Z., et al. (1999). The reform of the rural cooperative medical system in the People's Republic of China: Interim experience in 14 pilot counties. Social Science \& Medicine, 48, 961-972.

Chamon, M.D., \& Prasad, E.S. (2011). Why are saving rates of urban households in China rising? American Economic Journal: Macroeconomics, 2(1), 93-130.

Chatterji, S., Kowal, P., Mathers, C., Naidoo, N., Verdes, E., Smith, J.P., et al. (2008). The health of aging populations in China and India. Health Affairs, 27(4), $1052-1063$.

Choukhmane, T., Coeurdacier, N., \& Jin, K. (2013). The one-child policy and household savings, Mimeo.

Chow, G. (1985). A model of Chinese national income determination. Journal of Political Economy, 93(4), 782-792.

Cifaldi, G., \& Neri, A. (2013). Asking income and consumption questions in the same survey: What are the risks? Bank of Italy, working paper series.

Crossley, T.F., \& Winter, J.K. (2012). Asking households about expenditures: What have we learned? Improving the measurement of consumer expenditures, NBER chapters. National Bureau of Economic Research.

Deb, P., \& Trivedi, P.K. (1997). Demand for medical care by the elderly: A finite mixture approach. Journal of Applied Econometrics, $12,313-336$.

Feng, J., He, L., \& Sato, H. (2011). Public pension and household saving: Evidence from urban China. Journal of Comparative Economics, 39(4), 470-485.

Gao, J., Raven, J., \& Tang, S. (2007). Hospitalization among elderly in urban China. Health Policy, 84, 210-219.

Gao, J., Tang, S., Tolhurst, R., \& Rao, K. (2001). Changing access to health services in urban China: Implications for equity. Health Policy and Planning, 16(3), 302-312.

Herd, R., Hu, Y.W., \& Koen, V. (2010). Providing greater old-age security in China, OECD, economics department.

Impavido, G., Hu, Y.W., \& Li, X. (2009). Governance and fund management in the Chinese pension system, IMF WP/09/246.

Kraay, A. (2000). Household saving in China. World Bank Economic Review, 14(3), 545-570.

Liu, Y. (2002). Reforming China's urban health insurance system. Health Policy, 60, 133-150.

Liu, Y., Rao, K., Wu, J., \& Gakidou, E. (2008). China's health system performance. The Lancet, 372(9653), $1914-1923$.

Liu, G.G., \& Zhao, Z. (2006). Urban employee health insurance reform and the impact on out-of-pocket payment in China. International Journal of Health Planning and Management, 21(3), 211-228.

Ma, G., \& Yi, W. (2010). China's high saving rate: Myth and reality, BIS working papers 312. Bank for International Settlements.

Ministry of Labor and Social Security (1999). The policy options for supplementary medical insurance in China. Mimeo.

Modigliani, F., \& Cao, S.L. (2004). The Chinese saving puzzle and the life-cycle hypothesis. Journal of Economic Literature, 42(1), 145-170.

Moore, J.C., Stinson, L.L., \& Welniak, E.J. (2000). Income measurement error in surveys: A review. Journal of Official Statistics, 16, $331-361$.

Mu, R. (2013). Regional disparities in self reported health: Evidence from Chinese older adults. Health Economics. http://dx.doi.org/10.1002/hec.2929.

Nabar, M. (2011). Targets, interest rates, and household saving in urban China. IMF Working Paper 11/223.

National Bureau of Statistics of China (2003). The Chinese statistical yearbook 2003. China Statistics Press.

OECD (2010). Paris: OECD Economic Surveys: China.

Pedace, R., \& Bates, N. (2000). Using administrative records to assess earnings reporting error in the survey of income and program participation. Journal of Economic and Social Measurement, 26, 173-192.

Peng, W., et al. (2012). The trajectory of consumption in economic transition. China international capital company macroeconomic report, May 6, 2012.

Perkins, D. (2012). Rapid growth and changing economic structure: The expenditure side story and its implications for China. China Economic Review, 23(3), 501-511.

Pudney, S. (2008). Heaping and leaping: Survey response behaviour and the dynamics of self reported consumption expenditure. ISER working paper series 2008-09. Institute for Social and Economic Research.

Qian, Y. (1988). Urban and rural household saving in China. IMF Staff Papers, 35(4), 592-627.

Strauss, J., Lei, X., Park, A., Shen, Y., Smith, J., Yang, Z., et al. (2011). Health outcomes and socio-economic status among the elderly in China: Evidence from the CHARLS pilot. Journal of Population Ageing, 3, 111-143.

Wagstaff, A., \& Lindelow, M. (2008). Can insurance increase financial risk? The curious case of health insurance in China. Journal of Health Economics, 27(4), 990-1005.

Wagstaff, A., Yip, W., Lindelow, M., \& Hsiao, W. (2009). China's health system and its reform: A review of recent studies. Health Economics, 18, S7-S23.

Wang, Y. (1995). Permanent income and wealth accumulation: A cross-sectional study of Chinese urban and rural households. Economic Development and Cultural Change, 43(3), 522-550.

Wang, Y., \& Murie, A. (2000). Social and spatial implications of housing reform in China. International Journal of Urban and Regional Research, $24,397-417$.

Wang, X., \& Wen, Y. (2011). Can rising housing prices explain China's high household saving rate? Review, 93(2) (Federal Reserve Bank of San Louis).

Wang, Q., \& Zhang, S. (2009). China's under-consumption over-stated. A Morgan Stanley research report, September 15.

Wei, S.J., \& Zhang, X. (2011). The competitive saving motive: Evidence from rising sex ratios and savings rates in China. Journal of Political Economy, 119, 511-564.

Wen, Y. (2010). Saving and growth under borrowing constraints explaining the "high saving rate" puzzle. Working paper 2009-045C. Federal Reserve Bank of San Louis.

Yang, D.T., Zhang, J., \& Zhou, S. (2010). Why are saving rates so high in China? Working paper 16771. National Bureau of Economic Research.

Yip, W., \& Hsiao, W. (2009). China's health care reform: A tentative assessment. China Economic Review, 20(4), 613-619.

Zhang, J., \& Zhu, T. (2014). Re-estimating China's underestimated consumption. Comparative Economic Studies. http://dx.doi.org/10.1057/ces.2014.34.

Zhao, Z. (2008). Health demand and health determinants in China. Journal of Chinese Economic and Business Studies, 6(1), 77-98.

Zhu, T., \& Zhang, J. (2012). Is China's consumption rate too low? FT Chinese. (December 31, 2012) http://www.ftchinese.com/story/001048246 